Research Article

\title{
Characteristic Value Method of Well Test Analysis for Horizontal Gas Well
}

\author{
Xiao-Ping Li, ${ }^{1}$ Ning-Ping Yan, ${ }^{1,2}$ and Xiao-Hua $\operatorname{Tan}^{1}$ \\ ${ }^{1}$ State Key Laboratory of Oil and Gas Reservoir Geology and Exploitation, Southwest Petroleum University, Xindu Road 8 , \\ Chengdu 610500, China \\ ${ }^{2}$ No. 1 Gas Production Plant of PetroChina Changqing Oilfield Company, Yinchuan 750006, China
}

Correspondence should be addressed to Xiao-Hua Tan; xiaohua-tan@163.com

Received 16 May 2014; Accepted 28 July 2014; Published 25 September 2014

Academic Editor: Kim M. Liew

Copyright (C) 2014 Xiao-Ping Li et al. This is an open access article distributed under the Creative Commons Attribution License, which permits unrestricted use, distribution, and reproduction in any medium, provided the original work is properly cited.

\begin{abstract}
This paper presents a study of characteristic value method of well test analysis for horizontal gas well. Owing to the complicated seepage flow mechanism in horizontal gas well and the difficulty in the analysis of transient pressure test data, this paper establishes the mathematical models of well test analysis for horizontal gas well with different inner and outer boundary conditions. On the basis of obtaining the solutions of the mathematical models, several type curves are plotted with Stehfest inversion algorithm. For gas reservoir with closed outer boundary in vertical direction and infinite outer boundary in horizontal direction, while considering the effect of wellbore storage and skin effect, the pseudopressure behavior of the horizontal gas well can manifest four characteristic periods: pure wellbore storage period, early vertical radial flow period, early linear flow period, and late horizontal pseudoradial flow period. For gas reservoir with closed outer boundary both in vertical and horizontal directions, the pseudopressure behavior of the horizontal gas well adds the pseudosteady state flow period which appears after the boundary response. For gas reservoir with closed outer boundary in vertical direction and constant pressure outer boundary in horizontal direction, the pseudopressure behavior of the horizontal gas well adds the steady state flow period which appears after the boundary response. According to the characteristic lines which are manifested by pseudopressure derivative curve of each flow period, formulas are developed to obtain horizontal permeability, vertical permeability, skin factor, reservoir pressure, and pore volume of the gas reservoir, and thus the characteristic value method of well test analysis for horizontal gas well is established. Finally, the example study verifies that the new method is reliable. Characteristic value method of well test analysis for horizontal gas well makes the well test analysis process more simple and the results more accurate.
\end{abstract}

\section{Introduction}

Recent years have seen the ever-growing application of horizontal wells technology, which aroused considerable interest in the exploration of horizontal well test analysis [1-4]. In order to surmount the challenges in estimating horizontal well productivity and parameters, analytical solutions for interpreting transient pressure behavior of horizontal wells have attracted great attention.

Numerous studies on the pressure transient analysis of horizontal wells have been documented extensively in the literature. Combined with Newman's product method, Gringarten and Ramey [5] found an access to solve the unsteady-flow problems in reservoirs by means of the use of source and Green's function. Clonts and Ramey [6] presented an analytical solution for interpreting the transient pressure behavior of horizontal drain holes located in the heterogeneous reservoir. On the basis of finite Fourier transforms, Goode and Thambynayagam [7] addressed a solution for horizontal wells with infinite-conductivity in the semi-infinite reservoir. Ozkan and Rajagopal [8] demonstrated a derivative approach to analyze the pressuretransient behavior of horizontal wells, which revealed the relationship between the dimensionless well length and the horizontal-well pressure responses. Odeh and Babu [9] indicated that four significant flow periods could be 
observed during the process of horizontal well transient pressure behavior, which was further consolidated by the buildup and drawdown equations. Thompson and Temeng [10] introduced the automatic type curve matching method in analyzing multirate horizontal well pressure transient data through nonlinear regression analysis techniques. Rahavan et al. [11] employed a mathematical model to identify the features of pressure responses of a horizontal well with multiple fractures. Equipped with Laplace transformation and boundary element method, Zerzar and Bettam [12] addressed an analytical model for horizontal wells with finite conductivity vertical fractures. By extrapolating the transient pressure data, a simplified approach to predict well production was presented by Whittle et al. [13].

Owing to the imperfection of common well test analysis methods including the semilog data plotting analysis technique $[14,15]$, type curve matching analysis method $[16,17]$, and automatic fitting analysis method [18], it is inconvenient to apply those methods during the process of analyzing and determining reservoir parameters. Therefore, this paper presents the characteristic value method of well test analysis for horizontal gas well for the sake of overcoming conventional limitations. This method involves two steps. The first step is to develop formulas to calculate gas reservoir fluid flow parameters according to the characteristic lines manifested by pseudopressure derivative curves of each flowing period. The next step is to utilize these formulas to complete the well test analysis for horizontal gas well by means of combining the measured pressure with the pseudopressure derivative curve. The characteristic value method of well test analysis for horizontal gas well enriches and develops the well test analysis theory and method.

\section{Mathematical Models and Solutions of Well Test Analysis for Horizontal Gas Well}

The hypothesis: the formation thickness is $h$, the initial formation pressure of gas reservoir is $p_{i}$ and equal everywhere, the gas reservoir is anisotropic, the horizontal permeability is $K_{h}$, the vertical permeability is $K_{v}$, horizontal section length is $2 L$, and the position of horizontal section in the gas reservoir which is parallel to the closed top and bottom boundary is $z_{w}$. The surface flow rate of horizontal gas well is $q_{s c}$ and assumed to be constant. Single-phase compressible gas flow obeys Darcy law and the effect of gravity and capillary pressure is ignored. The physical model of horizontal gas well seepage is illustrated in Figure 1.

Considering the complexity of the seepage flow mechanism of horizontal gas well and in order to make the mathematical model's solving and calculation more simple, the establishment of mathematical models are divided into two parts: one is to ignore the effect of wellbore storage and skin effect; the other is to consider the effect of wellbore storage and skin effect $[19,20]$.

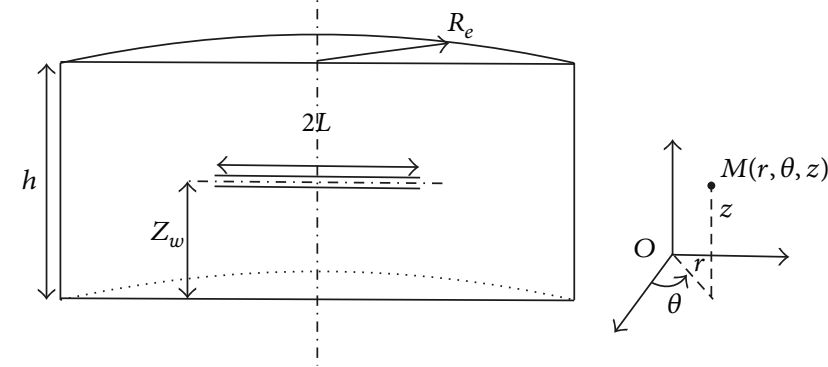

FIgURE 1: Physical model of horizontal gas well seepage.

2.1. The Mathematical Models without Considering the Effect of Wellbore Storage and Skin. The diffusivity equation is expressed by Ozkan and Raghavan [21]:

$$
\frac{1}{r_{D}} \frac{\partial}{\partial r_{D}}\left(r_{D} \frac{\partial m_{D}}{\partial r_{D}}\right)+L_{D}^{2} \frac{\partial^{2} m_{D}}{\partial z_{D}^{2}}=\left(h_{D} L_{D}\right)^{2} \frac{\partial m_{D}}{\partial t_{D}} .
$$

Initial condition is

$$
m_{D}\left(r_{D}, 0\right)=0 .
$$

Inner boundary condition is

$$
\begin{aligned}
\lim _{\varepsilon \rightarrow 0}\left[\lim _{r_{D} \rightarrow 0} \int_{z_{w D}-\varepsilon / 2}^{z_{w D}+\varepsilon / 2} r_{D} \frac{\partial m_{D}}{\partial r_{D}} d z_{w D}\right] \\
\quad= \begin{cases}0, & z_{D}>\left(z_{w D}+\frac{\varepsilon}{2}\right) \\
-\frac{1}{2}, & \left(z_{w D}+\frac{\varepsilon}{2}\right) \geq z_{D} \geq\left(z_{w D}-\frac{\varepsilon}{2}\right) \\
0, & z_{D}<\left(z_{w D}-\frac{\varepsilon}{2}\right),\end{cases}
\end{aligned}
$$

where $\varepsilon$ is a tiny variable.

Infinite outer boundary condition in horizontal direction is

$$
\lim _{r_{D} \rightarrow \infty} m_{D}\left(r_{D}, t_{D}\right)=0
$$

Closed outer boundary condition in horizontal direction is

$$
\left.\frac{\partial m_{D}}{\partial r_{D}}\right|_{r_{D}=r_{e D}}=0
$$

Constant pressure outer boundary condition in horizontal direction is

$$
\left.m_{D}\right|_{r_{D}=r_{e D}}=0 .
$$

Closed outer boundary conditions in vertical direction are

$$
\left.\frac{\partial m_{D}}{\partial z_{D}}\right|_{z_{D}=1}=0,\left.\quad \frac{\partial m_{D}}{\partial z_{D}}\right|_{z_{D}=0}=0
$$


The dimensionless variables are defined as follows:

$$
\begin{gathered}
m_{D}=\frac{78.489 K_{h} h}{q_{s c} T}\left(m_{i}-m\right), \quad t_{D}=\frac{3.6 K_{h} t}{\phi \mu c_{t} r_{w}^{2}}, \\
L_{D}=\frac{L}{h} \sqrt{\frac{K_{v}}{K_{h}}}, \quad h_{D}=\frac{h}{r_{w}} \sqrt{\frac{K_{h}}{K_{v}}}, \\
z_{D}=\frac{z}{h}, \quad z_{r D}=z_{w D}+r_{w D} L_{D}, \\
z_{w D}=\frac{z_{w}}{h}, \quad r_{D}=\frac{r}{L}, \\
r_{e D}=\frac{r_{e}}{L}, \quad r_{w D}=\frac{r_{w}}{L} .
\end{gathered}
$$

The defined gas pseudopressure is

$$
m(p)=2 \int_{p_{\mathrm{ref}}}^{p} \frac{p}{\mu(p) Z(p)} d p .
$$

2.2. The Mathematical Model with Considering the Effect of Wellbore Storage and Skin. According to Duhamel's principle [22] and the superposition principle, while using the definition of dimensionless variables, the mathematical model of horizontal gas well with considering the effect of wellbore storage and skin is derived as follows:

$$
\begin{aligned}
m_{w D}= & m_{D}+\int_{0}^{t_{D}} C_{D} \frac{d m_{w D}}{d \tau_{D}} \frac{d m_{w D}\left(t_{D}-\tau_{D}\right)}{d \tau_{D}} d \tau_{D} \\
& +\left(1-C_{D} \frac{d m_{w D}}{d \tau_{D}}\right) h_{D} S,
\end{aligned}
$$

where

$$
C_{D}=\frac{C}{2 \pi \phi C_{t} h L^{2}}
$$

2.3. The Solutions of the Mathematical Models. The solutions of the mathematical models $[23,24]$ at various outer boundary conditions can be obtained by applying source function and integral transform and taking the Laplace transform to $\bar{s}$ with respect to $t_{D}$.

For gas reservoir with closed outer boundary in vertical direction and infinite outer boundary in horizontal direction, according to (1), (2), (3), (4), and (7), the dimensionless bottomhole pseudopressure of horizontal gas well in the Laplace space can be obtained. This results in

$$
\begin{gathered}
\bar{m}_{D}=\frac{1}{2 \bar{s}}\left\{\int_{-1}^{1} K_{0}\left(\sqrt{\left(x_{D}-\alpha\right)^{2}} \varepsilon_{0}\right) d \alpha\right. \\
+2 \sum_{n=1}^{\infty} \int_{-1}^{1} K_{0}\left(\sqrt{\left(x_{D}-\alpha\right)^{2}} \varepsilon_{n}\right) \cos \left(\beta_{n} z_{r D}\right) \\
\left.\times \cos \left(\beta_{n} z_{w D}\right) d \alpha\right\},
\end{gathered}
$$

where

$$
\begin{gathered}
\beta_{n}=n \pi, \\
\varepsilon_{n}=\sqrt{\bar{s}\left(h_{D} L_{D}\right)^{2}+\beta_{n} L_{D}^{2}} .
\end{gathered}
$$

For gas reservoir with closed outer boundary both in vertical and horizontal direction, according to (1), (2), (3), (5), and (7), the dimensionless bottomhole pseudopressure of horizontal gas well in the Laplace space can be obtained. This results in

$$
\begin{gathered}
\bar{m}_{D}=\frac{1}{2 \bar{s}}\left\{\int_{-1}^{1} K_{0}\left(\sqrt{\left(x_{D}-\alpha\right)^{2}} \varepsilon_{0}\right) d \alpha\right. \\
+\frac{K_{1}\left(r_{e D} \varepsilon_{0}\right)}{I_{1}\left(r_{e D} \varepsilon_{0}\right)} \int_{-1}^{1} I_{0}\left(\sqrt{\left(x_{D}-\alpha\right)^{2}} \varepsilon_{0}\right) d \alpha \\
+2 \sum_{n=1}^{\infty}\left[\int_{-1}^{1} K_{0}\left(\sqrt{\left(x_{D}-\alpha\right)^{2}} \varepsilon_{n}\right) d \alpha\right. \\
+\frac{K_{1}\left(r_{e D} \varepsilon_{n}\right)}{I_{1}\left(r_{e D} \varepsilon_{n}\right)} \int_{-1}^{1} I_{0}\left(\sqrt{\left(x_{D}-\alpha\right)^{2}} \varepsilon_{n}\right) d \alpha \\
\left.\left.\cdot \cos \left(\beta_{n} z_{r D}\right) \cos \left(\beta_{n} z_{w D}\right)\right]\right\} .
\end{gathered}
$$

For gas reservoir with closed outer boundary in vertical direction and constant pressure outer boundary in horizontal direction, according to (1), (2), (3), (6), and (7), the dimensionless bottomhole pseudopressure of horizontal gas well in Laplace space can be obtained. This results in

$$
\begin{gathered}
\bar{m}_{D}=\frac{1}{2 \bar{s}}\left\{\int_{-1}^{1} K_{0}\left(\sqrt{\left(x_{D}-\alpha\right)^{2}} \varepsilon_{0}\right) d \alpha\right. \\
-\frac{K_{0}\left(r_{e D} \varepsilon_{0}\right)}{I_{0}\left(r_{e D} \varepsilon_{0}\right)} \int_{-1}^{1} I_{0}\left(\sqrt{\left(x_{D}-\alpha\right)^{2}} \varepsilon_{0}\right) d \alpha \\
+2 \sum_{n=1}^{\infty}\left[\int_{-1}^{1} K_{0}\left(\sqrt{\left(x_{D}-\alpha\right)^{2}} \varepsilon_{n}\right) d \alpha\right. \\
-\frac{K_{0}\left(r_{e D} \varepsilon_{n}\right)}{I_{0}\left(r_{e D} \varepsilon_{n}\right)} \int_{-1}^{1} I_{0}\left(\sqrt{\left(x_{D}-\alpha\right)^{2} \varepsilon_{n}}\right) d \alpha \\
\left.\left.\cdot \cos \left(\beta_{n} z_{r D}\right) \cos \left(\beta_{n} z_{w D}\right)\right]\right\} .
\end{gathered}
$$

Making the Laplace transform to $\bar{s}$ with respect to $t_{D} / C_{D}$, (10) can be solved for the dimensionless bottomhole pseudopressure of horizontal gas well considering the effect of wellbore storage and skin in the Laplace space. This results in

$$
\bar{m}_{w D}=\frac{\bar{s} \bar{m}_{D}+h_{D} S}{\bar{s}+\bar{s}^{2}\left(\bar{s} \bar{m}_{D}+h_{D} S\right)}=\frac{1}{\bar{s}\left(\bar{s}+1 /\left(\bar{s} \bar{m}_{D}+h_{D} S\right)\right)} .
$$




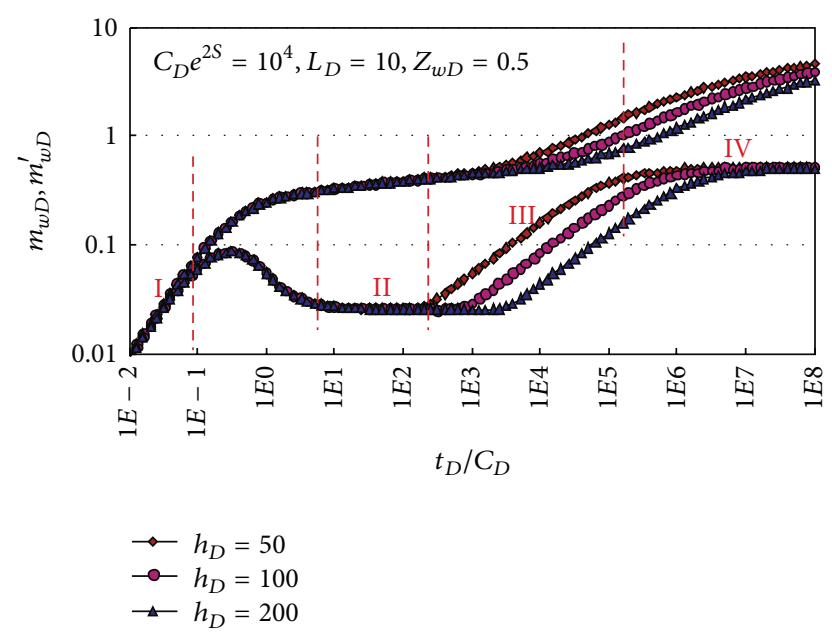

FIGURE 2: Well test analysis type curve of horizontal well in gas reservoir with infinite outer boundary.

\section{Type Curves of Well Test Analysis for Horizontal Gas Well}

3.1. Gas Reservoir with Infinite Outer Boundary in Horizontal Direction. For gas reservoir with infinite outer boundary in horizontal direction, according to (12) which is the solution of horizontal well seepage mathematical model, while combining with (16), the type curve of well test analysis for horizontal gas well can be plotted with Stehfest inversion algorithm, as shown in Figure 2.

As seen from Figure 2, for gas reservoir with infinite outer boundary in horizontal direction, the pseudopressure behavior of horizontal gas well can manifest four characteristic periods: pure wellbore storage period (I), early vertical radial flow period (II), early linear flow period (III), and late horizontal pseudoradial flow period (IV).

3.1.1. Pure Wellbore Storage Period. The characteristic of pure wellbore storage period of horizontal well is the same as vertical well, which is manifested as a $45^{\circ}$ straight line segment on the log-log plot of $m_{w D}, m_{w D}^{\prime}$ versus $t_{D} / C_{D}$, and the duration of this period is affected by wellbore storage and skin effect.

Expressions of dimensionless bottomhole pseudopressure and pseudopressure derivative during this period can be obtained. This results in

$$
\begin{gathered}
m_{w D}=\frac{t_{D}}{C_{D}}, \\
m_{w D}^{\prime}=\frac{d m_{w D}}{d \ln \left(t_{D} / C_{D}\right)}=\frac{t_{D}}{C_{D}} .
\end{gathered}
$$

3.1.2. Early Vertical Radial Flow Period. The early vertical radial flow period appears after the effect of wellbore storage; the characteristic of this period is manifested as a horizontal straight line segment on the log-log plot of $m_{w D}^{\prime}$ versus $t_{D} / C_{D}$. The pseudopressure behavior of this period is affected by formation thickness, horizontal section length, and the

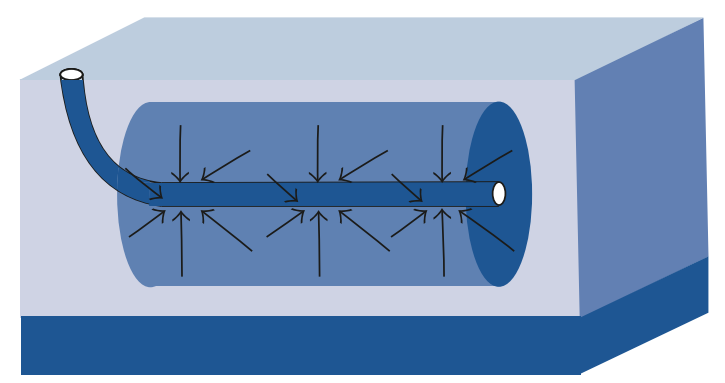

FIGURE 3: The schematic diagram of early vertical radial flow.

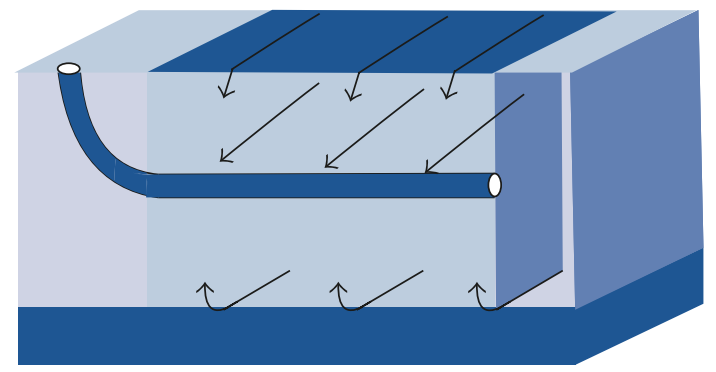

FIgURE 4: The schematic diagram of early linear flow.

position of horizontal section in the gas reservoir. The flow regime of this period is shown in Figure 3.

Expressions of dimensionless bottomhole pseudopressure and pseudopressure derivative during this period can be obtained. This results in

$$
\begin{gathered}
m_{w D}=\frac{1}{4 L_{D}}\left[\ln 2.25\left(\frac{t_{D}}{C_{D}}\right)+\ln C_{D} e^{2 S}\right], \\
m_{w D}^{\prime}=\frac{d m_{w D}}{d \ln \left(t_{D} / C_{D}\right)}=\frac{1}{4 L_{D}} .
\end{gathered}
$$

3.1.3. Early Linear Flow Period. The early linear flow period appears after the early vertical radial flow period. The characteristic of this period is manifested as a straight line segment with a slope of 0.5 on the log-log plot of $m_{w D}^{\prime}$ versus $t_{D} / C_{D}$. This characteristic describes the linear flow of fluid from formation to horizontal section. The pseudopressure behavior of this period is affected by dimensionless formation thickness $h_{D}$, dimensionless horizontal section length $L_{D}$, and the position of horizontal section in the gas reservoir $z_{w D}$. The flow regime of this period is shown in Figure 4.

Expressions of dimensionless bottomhole pseudopressure and pseudopressure derivative during this period can be obtained. This results in

$$
\begin{gathered}
m_{w D}=2 r_{w D} \sqrt{\pi t_{D}}+S \\
m_{w D}^{\prime}=\frac{d m_{w D}}{d \ln \left(t_{D} / C_{D}\right)}=r_{w D} \sqrt{\pi t_{D}}
\end{gathered}
$$

3.1.4. Late Horizontal Pseudoradial Flow Period. The late horizontal pseudoradial flow period appears after the early linear flow period. The characteristic of this period is manifested 


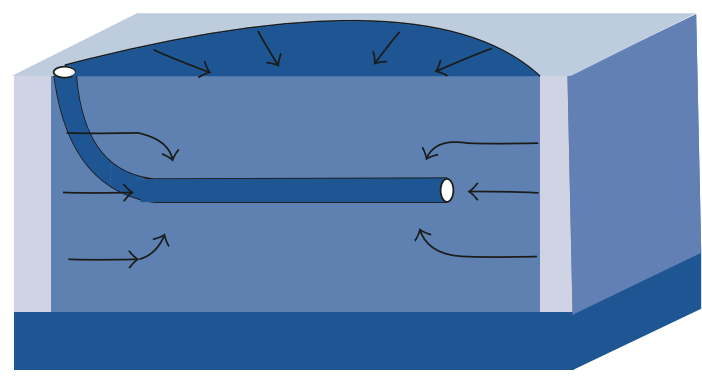

FIGURE 5: The schematic diagram of late horizontal pseudoradial flow.

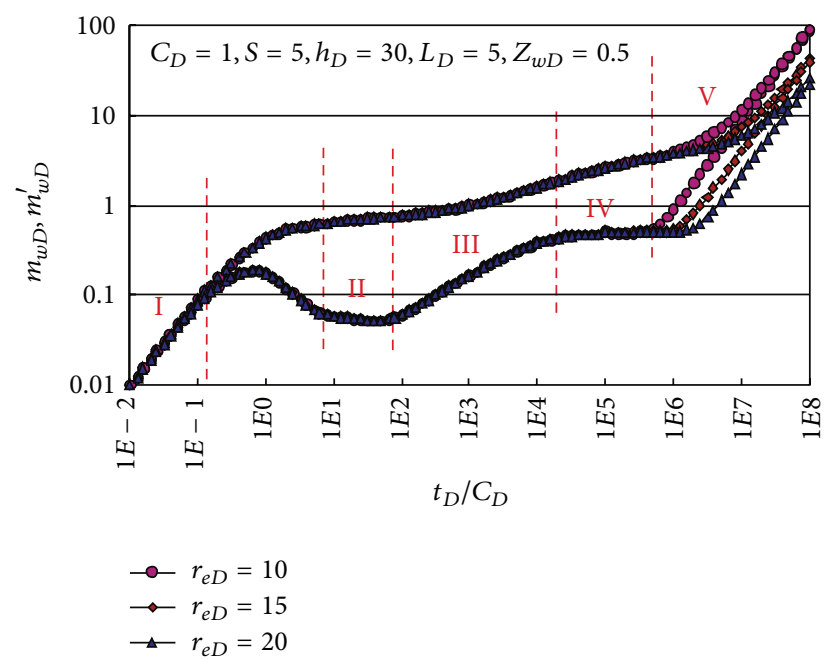

Figure 6: Well test analysis type curve of horizontal well in gas reservoir with closed outer boundary.

as a horizontal straight line segment with the value of 0.5 on the log-log plot of $m_{w D}^{\prime}$ versus $t_{D} / C_{D}$. This characteristic describes the horizontal pseudoradial flow of fluid from formation horizontal plane in the distance to horizontal section. The flow regime of this period is shown in Figure 5.

Expressions of dimensionless bottomhole pseudopressure and pseudopressure derivative during this period can be obtained. This results in

$$
\begin{gathered}
m_{w D}=\frac{1}{2}\left[\ln \left(\frac{r_{w D} t_{D}}{C_{D}}\right)+\ln C_{D} e^{2 S}\right], \\
m_{w D}^{\prime}=\frac{d m_{w D}}{d \ln \left(t_{D} / C_{D}\right)}=\frac{1}{2} .
\end{gathered}
$$

\subsection{Gas Reservoir with Closed Outer Boundary in Horizontal} Direction. For gas reservoir with closed outer boundary in horizontal direction, according to (14) which is the solution of horizontal well seepage mathematical model, while combining with (16), the type curve of well test analysis for horizontal gas well can be plotted with Stehfest inversion algorithm, as shown in Figure 6.

As seen from Figure 6, for gas reservoir with closed outer boundary in horizontal direction, the pseudopressure behavior of horizontal gas well can manifest five characteristic

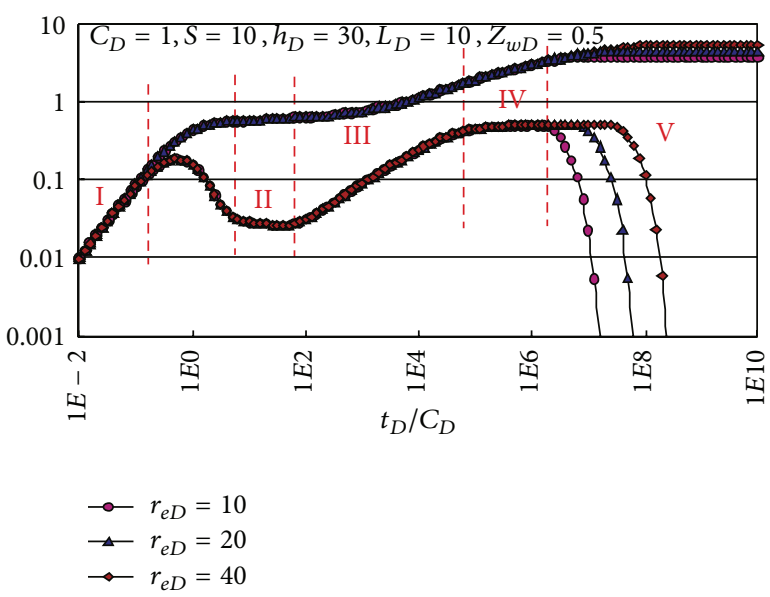

FIGURE 7: Well test analysis type curve of horizontal well in gas reservoir with constant pressure outer boundary.

periods. The previous four periods of gas reservoir with closed outer boundary are exactly the same as gas reservoir with infinite outer boundary, but the pseudopressure behavior of the horizontal gas well adds the pseudosteady state flow period $(\mathrm{V})$ which appears after the boundary response. The characteristic of the pseudosteady state flow period is manifested as a straight line segment with a slope of 1 on the log-log plot of $m_{w D}, m_{w D}^{\prime}$ versus $t_{D} / C_{D}$. The greater the distance of the outer boundary, the later the appearance of the pseudosteady state flow period. The smaller the distance of the outer boundary, the sooner the appearance of the pseudosteady state flow period.

Expressions of dimensionless bottomhole pseudopressure and pseudopressure derivative during the pseudosteady state flow period can be obtained. This results in

$$
\begin{gathered}
m_{w D}=2 \pi\left(\frac{r_{w D}}{r_{e D}}\right)^{2} t_{D}+S \\
m_{w D}^{\prime}=\frac{d m_{w D}}{d \ln \left(t_{D} / C_{D}\right)}=2 \pi\left(\frac{r_{w D}}{r_{e D}}\right)^{2} t_{D}
\end{gathered}
$$

3.3. Gas Reservoir with Constant Pressure Outer Boundary in Horizontal Direction. For gas reservoir with constant pressure outer boundary in horizontal direction, according to (15) which is the solution of horizontal well seepage mathematical model, while combining with (16), the type curve of well test analysis for horizontal gas well can be plotted with Stehfest inversion algorithm, as shown in Figure 7.

As seen from Figure 7, for gas reservoir with constant pressure outer boundary in horizontal direction, the pseudopressure behavior of horizontal gas well can manifest five characteristic periods; the previous four periods of gas reservoir with constant pressure outer boundary are exactly the same as gas reservoir with infinite outer boundary, but the pseudopressure behavior of the horizontal gas well adds the steady state flow period $(\mathrm{V})$ which appears after the boundary response. The occurrence time of the steady state flow period is affected by the outer boundary distance 
in horizontal direction. The smaller the distance of the outer boundary, the sooner the appearance of the steady state flow period. The greater the distance of the outer boundary, the later the appearance of the steady state flow period.

3.4. Characteristic Value Method of Well Test Analysis for Horizontal Gas Well. The characteristic value method of well test analysis for horizontal gas well can determine the gas reservoir fluid flow parameters according to the characteristic lines which are manifested by pseudopressure derivative curve of each flow period on the log-log plot.

3.4.1. Pure Wellbore Storage Period. The characteristic of pure wellbore storage period of horizontal well is manifested as a straight line segment with a slope of 1 on the log-log plot of $m_{w D}, m_{w D}^{\prime}$ versus $t_{D} / C_{D}$. The expression of dimensionless bottomhole pseudopressure during this period is

$$
m_{w D}=\frac{t_{D}}{C_{D}} .
$$

Equation (22) can be converted to dimensional form, and then according to the time and pressure data during pure wellbore storage period, the method to determine the wellbore storage coefficient can be obtained. By plotting the log-log plot of $\Delta m, \Delta m^{\prime}$ versus $t$, the wellbore storage coefficient can be determined by the straight line segment with a slope of 1 on the log-log plot.

The following can be obtained from the definitions of dimensionless variables:

$$
\frac{t_{D}}{C_{D}}=\frac{3.6 K_{h} t / \phi \mu c_{t} r_{w}^{2}}{C / 2 \pi \phi c_{t} h L^{2}}=\frac{7.2 \pi K_{h} h L^{2}}{\mu r_{w}^{2}} \frac{t}{C} .
$$

According to (22), (23), and the definition of dimensionless pseudopressure, the wellbore storage coefficient can be obtained. This results in

$$
C=\frac{0.288 q_{s c} T}{\mu} \frac{L^{2}}{r_{w}^{2}} \frac{t}{\Delta m},
$$

where $t / \Delta m$ represents the actual value on the log-log plot of $\Delta m, \Delta m^{\prime}$ versus $t$ during the pure wellbore storage period.

\subsubsection{Early Vertical Radial Flow Period}

The Determination of Geometric Mean Permeability. The dimensionless bottomhole pseudopressure derivative curve is manifested as a horizontal straight line segment with the value of $1 /\left(4 L_{D}\right)$ during the early vertical radial flow period. The expression of dimensionless bottomhole pseudopressure derivative during this period is

$$
m_{w D}^{\prime}=\frac{d m_{w D}}{d \ln \left(t_{D} / C_{D}\right)}=\frac{1}{4 L_{D}} .
$$

According to the definitions of dimensionless variables, the dimensional form of (25) can be obtained. This results in

$$
\frac{78.489 K_{h} h}{q_{s c} T}\left(t \Delta m^{\prime}\right)_{\mathrm{er}}=\frac{1}{4(L / h) \sqrt{K_{v} / K_{h}}} .
$$

The geometric mean permeability of gas reservoir can be determined by (26). This results in

$$
\sqrt{K_{h} K_{v}}=\frac{3.185 \times 10^{-3} q_{s c} T}{L\left(t \Delta m^{\prime}\right)_{\mathrm{er}}},
$$

where $\left(t \Delta m^{\prime}\right)_{\mathrm{er}}$ represents the actual value on the log-log plot of $\Delta m^{\prime}$ versus $t$ during the early vertical radial flow period.

The Determination of Skin Factor and Initial Reservoir Pressure. The expression of dimensionless bottomhole pseudopressure during the early vertical radial flow period is

$$
m_{w D}=\frac{1}{4 L_{D}}\left[\ln 2.25\left(\frac{t_{D}}{C_{D}}\right)+\ln C_{D} e^{2 S}\right] .
$$

According to the definitions of dimensionless variables and (28), the skin factor can be obtained. This results in

$$
S=0.5\left[\frac{\Delta m_{\mathrm{er}}}{\left(t \Delta m^{\prime}\right)_{\mathrm{er}}}-\ln \frac{K_{h} t_{\mathrm{er}}}{\phi \mu C_{t} r_{w}^{2}}-0.80907\right],
$$

where $\Delta m_{\mathrm{er}}$ and $t_{\mathrm{er}}$ represent the pseudopressure difference and time corresponding to the $\left(t \Delta m^{\prime}\right)_{\mathrm{er}}$, respectively.

For pressure buildup analysis, when $\Delta t \rightarrow \infty$, the $\ln \Delta t /\left(\Delta t+t_{p}\right) \rightarrow 0$, (30) can be obtained through the use of the definitions of dimensionless variables and pseudopressure difference during the early vertical radial flow period:

$$
\frac{m_{i}-m_{w f}}{t \Delta m^{\prime}}=\ln t_{p D}+0.80907+2 S .
$$

The initial reservoir pseudopressure can be determined by (30). This results in

$$
m_{i}=m_{w f}+\left(t \Delta m^{\prime}\right)_{\mathrm{erb}}\left(\ln t_{p D}+0.80907+2 S\right)
$$

where $\left(t \Delta m^{\prime}\right)_{\text {erb }}$ represents the actual value on the pressure buildup log-log plot of $\Delta m^{\prime}$ versus $t$ during the early vertical radial flow period.

3.4.3. Early Linear Flow Period. The dimensionless bottomhole pseudopressure derivative curve is manifested as a straight line segment with the slope of 0.5 during the early linear flow period. According to the expression of dimensionless bottomhole pseudopressure derivative during this period and the definitions of dimensionless variables, the following can be obtained:

$$
\frac{78.489 K_{h} h}{q_{s c} T}\left(t \Delta m^{\prime}\right)_{l}=\frac{r_{w}}{L} \sqrt{\frac{3.6 \pi K_{h} t}{\phi \mu C_{t} r_{w}^{2}}} .
$$

The horizontal permeability of gas reservoir can be determined by (32). This results in

$$
\sqrt{K_{h}}=\frac{4.28 \times 10^{-2} q_{s c} T}{L h \sqrt{\phi \mu C_{t}}}\left[\frac{\sqrt{t}}{\left(t \Delta m^{\prime}\right)}\right]_{l},
$$


where $\left(t \Delta m^{\prime}\right)_{l}$ represents the actual value on the log-log plot of $\Delta m^{\prime}$ versus $t$ during the early linear flow period.

Combining (27) with (33), the vertical permeability can be obtained. This results in

$$
\sqrt{K_{v}}=7.44 \times 10^{-2} h \sqrt{\phi \mu C_{t}} \frac{\left[\left(t \Delta m^{\prime}\right) / \sqrt{t}\right]_{l}}{\left(t \Delta m^{\prime}\right)_{\mathrm{er}}} .
$$

3.4.4. Late Horizontal Pseudoradial Flow Period. The dimensionless bottomhole pseudopressure derivative curve is manifested as a horizontal straight line segment with the value of 0.5 during the late horizontal pseudoradial flow period. According to the expression of dimensionless bottomhole pseudopressure derivative during this period and the definitions of dimensionless variables, (35) can be obtained:

$$
\frac{78.489 K_{h} h}{q_{s c} T}\left(t \Delta m^{\prime}\right)_{\operatorname{lr}}=0.5 .
$$

The horizontal permeability of gas reservoir can be determined by (35). This results in

$$
K_{h}=\frac{6.37 \times 10^{-3} q_{s c} T}{h\left(t \Delta m^{\prime}\right)_{\mathrm{lr}}}
$$

where $\left(t \Delta m^{\prime}\right)_{\text {lr }}$ represents the actual value on the log-log plot of $\Delta m^{\prime}$ versus $t$ during the late horizontal pseudoradial flow period.

For pressure buildup analysis, when $\Delta t \rightarrow \infty$, the $\ln \Delta t /\left(\Delta t+t_{p}\right) \rightarrow 0$, (37) can be obtained through the use of the definitions of dimensionless variables and pseudopressure difference during the late horizontal pseudoradial flow period:

$$
\frac{m_{i}-m_{w f}}{\left(t \Delta m^{\prime}\right)_{\operatorname{lrb}}}=\ln r_{w D} t_{p D}+0.80907+2 S .
$$

The initial reservoir pseudopressure can be determined by (37). This results in

$$
m_{i}=m_{w f}+\left(t \Delta m^{\prime}\right)_{\operatorname{lrb}}\left(\ln r_{w D} t_{p D}+0.80907+2 S\right),
$$

where $\left(t \Delta m^{\prime}\right)_{\text {lrb }}$ represents the actual value on the pressure buildup log-log plot of $\Delta m^{\prime}$ versus $t$ during the late horizontal pseudoradial flow period.

3.4.5. Pseudosteady Flow Period. The dimensionless bottomhole pseudopressure derivative curve is manifested as a straight line segment with the slope of 1 during the pseudosteady flow period. According to the expression of dimensionless bottomhole pseudopressure derivative during this period and the definitions of dimensionless variables, (39) can be obtained:

$$
\frac{78.489 K_{h} h}{q_{s c} T}\left(t \Delta m^{\prime}\right)_{\mathrm{pp}}=\frac{7.2 \pi K_{h} t_{\mathrm{pp}}}{r_{e}^{2} h \phi \mu C_{t}} .
$$

The pore volume of gas reservoir can be determined by (39). This results in

$$
\pi r_{e}^{2} h \phi=\frac{0.905 q_{s c} T}{h \mu C_{t}} \frac{t_{\mathrm{pp}}}{\left(t \Delta m^{\prime}\right)_{\mathrm{pp}}},
$$

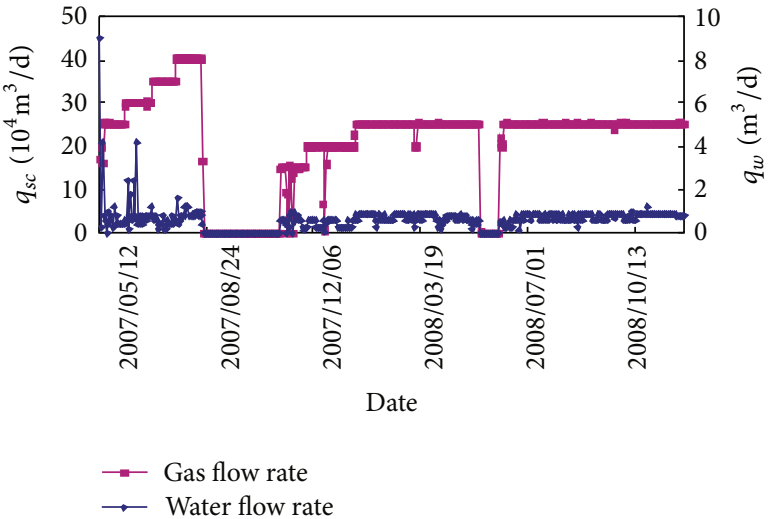

FIgURE 8: The gas flow rate and water flow rate curve of Longping 1 well.

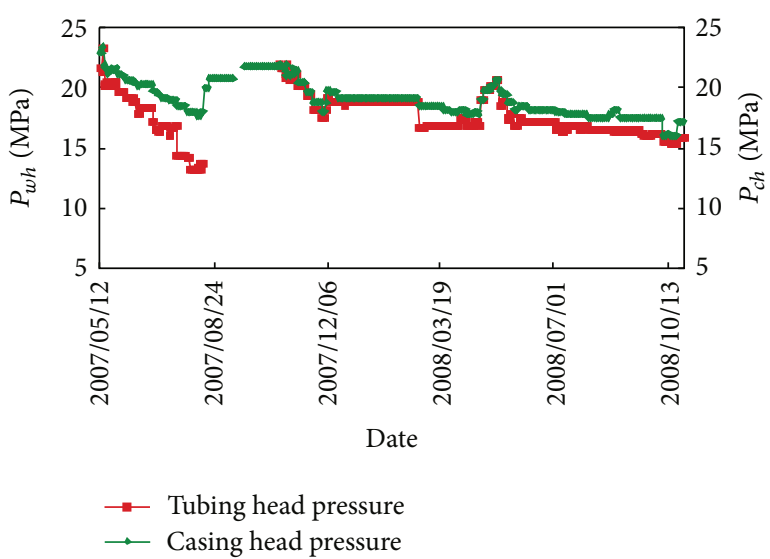

FIGURE 9: The tubing head pressure and casing head pressure curve of Longping 1 well.

where $\left(t \Delta m^{\prime}\right)_{\mathrm{pp}}$ represents the actual value on the log-log plot of $\Delta m^{\prime}$ versus $t$ during the pseudosteady flow period.

\section{Example Analysis}

The Longping 1 well is a horizontal development well in JingBian gas field, the well total depth is $4672 \mathrm{~m}$, the drilled formation name is Majiagou group, the mid-depth of reservoir is $3425.63 \mathrm{~m}$, and the well completion system is screen completion. According to the deliverability test during 26-29 December, 2006, the calculated absolute open flow was 94.26 $\times 10^{4} \mathrm{~m}^{3} / \mathrm{d}$. The commissioning data of Longping 1 well was in 12 May, 2007, the initial formation pressure was $29.39 \mathrm{MPa}$, before production, and the surface tubing pressure and casing pressure were both $23.90 \mathrm{MPa}$. The production performance curves of Longping 1 well are shown in Figures 8 and 9, respectively.

Longping 1 well has been conducted pressure buildup test during 14 August, 2007, and 23 October, 2007. The gas flow rate of Longping 1 well was $40 \times 10^{4} \mathrm{~m}^{3} / \mathrm{d}$ before the shut-in. The bottomhole pressure recovered from $22.38 \mathrm{MPa}$ to $27.83 \mathrm{MPa}$ during the pressure buildup test. Physical 


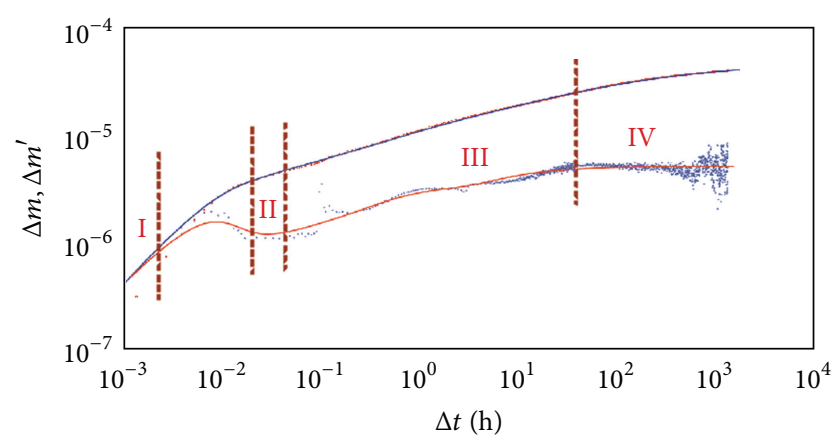

FIGURE 10: The pressure buildup log-log plot of Longping 1 well.

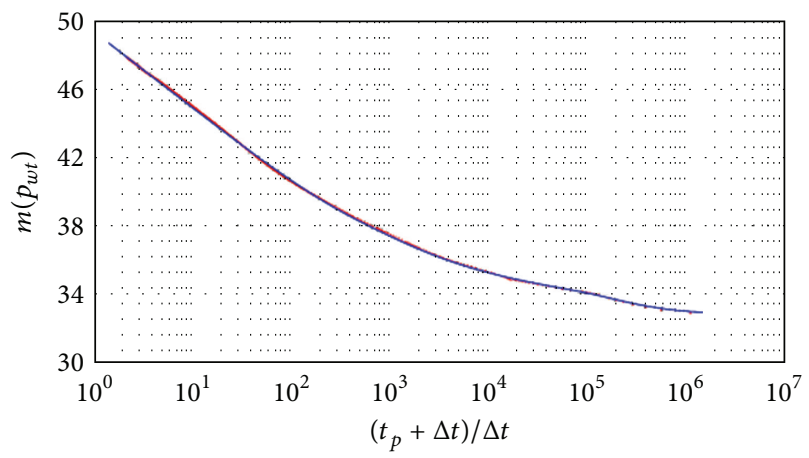

FIGURE 11: The pressure buildup semilog plot of Longping 1 well.

TABLE 1: Physical parameters of fluid and reservoir.

\begin{tabular}{lc}
\hline Parameter & Value \\
\hline Initial formation pressure $p_{i}(\mathrm{MPa})$ & 29.39 \\
Formation temperature $T\left({ }^{\circ} \mathrm{C}\right)$ & 95.80 \\
Formation thickness $h(\mathrm{~m})$ & 6.31 \\
Porosity $\phi(\%)$ & 7.77 \\
Initial water saturation $S_{\mathrm{wi}}(\%)$ & 13.60 \\
Well radius $r_{w}(\mathrm{~m})$ & 0.0797 \\
Gas gravity $\gamma_{g}$ & 0.608 \\
Gas deviation factor $Z$ & 0.9738 \\
Gas viscosity $\mu_{g}(\mathrm{mPa} \cdot \mathrm{s})$ & 0.0222 \\
\hline
\end{tabular}

TABLE 2: Well test analysis results of Longping 1 well.

\begin{tabular}{lc}
\hline Parameter & Parameter values \\
\hline Wellbore storage coefficient $C\left(\mathrm{~m}^{3} / \mathrm{MPa}\right)$ & 1.229 \\
Horizontal permeability $K_{h}(\mathrm{mD})$ & 7.742 \\
Vertical permeability $K_{v}(\mathrm{mD})$ & 0.039 \\
Flow capacity $K_{h} h(\mathrm{mD} \cdot \mathrm{m})$ & 48.857 \\
Skin factor $S$ & -2.49 \\
Effective horizontal section length $L(\mathrm{~m})$ & 198.37 \\
Reservoir pressure $p_{R}(\mathrm{MPa})$ & 28.385 \\
\hline
\end{tabular}

parameters of fluid and reservoir are shown in Table 1. The pressure buildup log-log plot of Longping 1 well is shown in Figure 10.

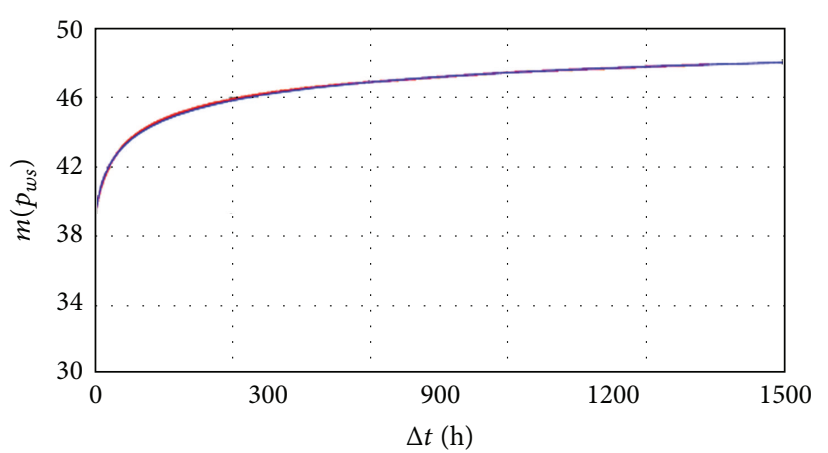

FIGURE 12: The pressure history matching plot of Longping 1 well.

As seen from the contrast between Figure 10 and well test analysis type curves of horizontal well, the pseudopressure behavior of Longping 1 well manifests four characteristic periods during the pressure buildup test: pure wellbore storage period (I), early vertical radial flow period (II), early linear flow period (III), and late horizontal pseudoradial flow period (IV).

Using the above characteristic value method of well test analysis for horizontal gas well, well test analysis results of Longping 1 well are shown in Table 2. The pressure buildup semilog plot and pressure history matching plot of Longping 1 well are shown in Figures 11 and 12, respectively.

\section{Summary and Conclusions}

The four main conclusions and summary of this study are as follows.

(1) On the basis of establishing the mathematical models of well test analysis for horizontal gas well and obtaining the solutions of the mathematical models, several type curves which can be used to identify flow regime have been plotted and the seepage characteristic of horizontal gas well has been analyzed.

(2) The expressions of dimensionless bottomhole pseudopressure and pseudopressure derivative during each characteristic period of horizontal gas well have been obtained; formulas have been developed to calculate gas reservoir fluid flow parameters.

(3) The example study verifies that the characteristic value method of well test analysis for horizontal gas well is reliable and practical.

(4) The characteristic value method of well test analysis, which has been included in the well test analysis software at present, has been widely used in vertical well. As long as the characteristic straight line segments which are manifested by pressure derivative curve appear, the reservoir fluid flow parameters can be calculated by the characteristic value method of well test analysis for vertical well. The proposed characteristic value method of well test analysis for 
horizontal gas well enriches and develops the well test analysis theory and method.

\section{Nomenclature}

$C: \quad$ Wellbore storage coefficient, $\mathrm{m}^{3} / \mathrm{MPa}$

$C_{D}$ : Dimensionless wellbore storage coefficient

$C_{t}$ : Total compressibility, $\mathrm{MPa}^{-1}$

$h$ : Reservoir thickness, $m$

$h_{D}$ : Dimensionless reservoir thickness

$I_{n}$ : Modified Bessel function of first kind of order $n$

$K_{h}$ : Horizontal permeability, $\mathrm{mD}$

$K_{n}$ : Modified Bessel function of second kind of order $n$

$K_{V}: \quad$ Vertical permeability, $\mathrm{mD}$

$L: \quad$ Horizontal section length, $m$

$L_{D}$ : Dimensionless horizontal section length

$m(p)$ : Pseudopressure, $\mathrm{MPa}^{2} / \mathrm{mPa} \cdot \mathrm{s}$

$m_{D}$ : Dimensionless pseudopressure

$m_{i}$ : Initial formation pseudopressure, $\mathrm{MPa}^{2} / \mathrm{mPa} \cdot \mathrm{s}$

$m_{w D}$ : Dimensionless bottomhole pseudopressure

$m_{w f}$ : Flowing wellbore pseudopressure, $\mathrm{MPa}^{2} / \mathrm{mPa} \cdot \mathrm{s}$

$m_{w D}^{\prime}:$ Derivative of $m_{w D}$

$\bar{m}_{D}$ : Laplace transform of $m_{D}$

$\bar{m}_{w D}:$ Laplace transform of $m_{w D}$

$\Delta m$ : Pseudopressure difference, $\mathrm{MPa}$

$\Delta m^{\prime}:$ Derivative of $\Delta m$

$p_{c h}:$ Casing head pressure, $\mathrm{MPa}$

$p_{i}$ : Initial formation pressure, $\mathrm{MPa}$

$p_{R}: \quad$ Reservoir pressure, $\mathrm{MPa}$

$p_{w h}$ : Tubing head pressure, $\mathrm{MPa}$

$p_{w s}:$ Flowing wellbore pressure at shut-in, $\mathrm{MPa}$

$q_{s c}: \quad$ Gas flow rate, $10^{4} \mathrm{~m}^{3} / \mathrm{d}$

$q_{w}$ : Water production rate, $\mathrm{m}^{3} / \mathrm{d}$

$r$ : $\quad$ Radial distance, $m$

$r_{D}$ : Dimensionless radial distance

$r_{e}: \quad$ Outer boundary distance, $\mathrm{m}$

$r_{e D}$ : Dimensionless outer boundary distance

$r_{w}$ : Wellbore radius, $\mathrm{m}$

$r_{w D}:$ Dimensionless wellbore radius

$S: \quad$ Skin factor

$\bar{s}$ : $\quad$ Laplace transform variable

$S_{w i}:$ Initial water saturation, fraction

$t: \quad$ Time, hours

$t_{D}$ : Dimensionless time

$t_{p}$ : Production time, hours

$t_{p D}:$ Dimensionless production time

$\Delta t: \quad$ Shut-in time, hours

T: $\quad$ Formation temperature, ${ }^{\circ} \mathrm{C}$

$z: \quad$ Vertical distance, $\mathrm{m}$

$z_{D}$ : Dimensionless vertical distance

$z_{w}$ : Horizontal section position, $\mathrm{m}$

$z_{w D}$ : Dimensionless horizontal section position

$Z: \quad$ Gas deviation factor

$\varepsilon$ : Tiny variable

$\phi$ : $\quad$ Porosity, fraction

$\mu$ : $\quad$ Gas viscosity, $\mathrm{mPa} \cdot \mathrm{s}$

$\gamma_{g}: \quad$ Gas gravity.
Subscripts

D: Dimensionless

er: Early

erb: Early of buildup

$h$ : Horizontal

$i$ : Initial

l: $\quad$ Linear

lr: Late horizontal pseudo-radial

lrb: Late horizontal pseudo-radial of buildup

pp: Pseudosteady flow period

$t$ : Total

$v$ : Vertical

$w f$ : Flowing wellbore

$w s$ : Shut-in wellbore.

\section{Conflict of Interests}

The authors declare that there is no conflict of interests regarding the publication of this paper.

\section{References}

[1] R. S. Nie, J. C. Guo, Y. L. Jia, S. Q. Zhu, Z. Rao, and C. G. Zhang, "New modelling of transient well test and rate decline analysis for a horizontal well in a multiple-zone reservoir," Journal of Geophysics and Engineering, vol. 8, no. 3, pp. 464-476, 2011.

[2] D. R. Yuan, H. Sun, Y. C. Li, and M. Zhang, "Multi-stage fractured tight gas horizontal well test data interpretation study," in Proceedings of the International Petroleum Technology Conference, March 2013.

[3] M. Mavaddat, A. Soleimani, M. R. Rasaei, Y. Mavaddat, and A. Momeni, "Well test analysis of Multiple Hydraulically Fractured Horizontal Wells (MHFHW) in gas condensate reservoirs," in Proceedings of the SPE/IADC Middle East Drilling Technology Conference and Exhibition (MEDT '11), pp. 39-48, October 2011.

[4] M. Mirza, P. Aditama, M. AL Raqmi, and Z. Anwar, "Horizontal well stimulation: a pilot test in southern Oman," in Proceedings of the SPE EOR Conference at Oil and Gas West Asia, April 2014.

[5] A. C. Gringarten and H. J. Ramey Jr., "The use of source and green's function in solving unsteady-flow problem in reservoir ," Society of Petroleum Engineers Journal, vol. 13, no. 5, pp. 285296, 1973.

[6] M. D. Clonts and H. J. Ramey, "Pressure transient analysis for wells with horizontal drainholes," in Proceedings of the SPE California Regional Meeting, Oakland, Calif, USA, April 1986, paper SPE 15116.

[7] P. A. Goode and R. K. M. Thambynayagam, "Pressure drawdown and buildup analysis of horizontal wells in anisotropic media," SPE Formation Evaluation, vol. 2, no. 4, pp. 683-697, 1987.

[8] E. Ozkan and R. Rajagopal, "Horizontal well pressure analysis," SPE Formation Evaluation, pp. 567-575, 1989.

[9] A. S. Odeh and D. K. Babu, "Transient flow behavior of horizontal wells. Pressure drawdown and buildup analysis," SPE Formation Evaluation, vol. 5, no. 1, pp. 7-15, 1990.

[10] L. G. Thompson and K. O. Temeng, "Automatic type-curve matching for horizontal wells," in Proceedings of the Production Operation Symposium, Oklahoma City, Okla, USA, 1993, paper SPE 25507. 
[11] R. S. Rahavan, C. C. Chen, and B. Agarwal, "An analysis of horizontal wells intercepted by multiple fractures," SPE27652 (Sep, pp. 235-245, 1997.

[12] A. Zerzar and Y. Bettam, "Interpretation of multiple hydraulically fractured horizontal wells in closed systems," in Proceedings of the SPE International Improved Oil Recovery Conference in Asia Pacific (IIORC '03), pp. 295-307, Alberta, Canada, October 2003.

[13] T. Whittle, H. Jiang, S. Young, and A. C. Gringarten, "Well production forecasting by extrapolation of the deconvolution of the well test pressure transients," in Proceedings of the SPE EUROPEC/EAGE Conference, Amsterdam, The Netherland, June 2009, SPE 122299 paper.

[14] C. C. Miller, A. B. Dyes, and C. A. Hutchinson, "The estimation of permeability and reservoir pressure from bottom-hole pressure buildup Characteristic," Journal of Petroleum Technology, pp. 91-104, 1950.

[15] D. R. Horner, "Pressure buildup in wells," in Proceedings of the 3rd World Petroleum Congress, Hague, The Netherlands, MayJune 1951, paper SPE 4135.

[16] R. Raghavan, "The effect of producing time on type curve analysis," Journal of Petroleum Technology, vol. 32, no. 6, pp. 1053-1064, 1980.

[17] D. Bourdet, "A new set of type curves simplifies well test analysis," World Oil, pp. 95-106, 1983.

[18] T. M. Hegre, "Hydraulically fractured horizontal well simulation," in Proceedings of the NPF/SPE European Production Operations Conference (EPOC '96), pp. 59-62, April 1996.

[19] R. G. Agarwal, R. Al-Hussaing, and H. J. Ramey, "An investigation of wellbore storage and skin effect in unsteady liquid flow: I. Analytical treatment," Society of Petroleum Engineers Journal, vol. 10, no. 3, pp. 291-297, 1970.

[20] H. J. J. Ramey and R. G. Agarwal, "Annulus unloading rates as influenced by wellbore storage and skin effect," Society of Petroleum Engineers Journal, vol. 12, no. 5, pp. 453-462, 1972.

[21] E. Ozkan and R. Raghavan, "New solutions for well-testanalysis problems: part 1-analytical considerations," SPE Formation Evaluation, 1991.

[22] L. G. Thompson, Analysis of variable rate pressure data using duhamels principle [Ph.D. thesis], University of Tulsa, Tulsa, Okla, USA, 1985.

[23] H. Stehfest, "Numerical inversion of laplace transforms," Communications of the ACM, vol. 13, no. 1, pp. 47-49, 1970.

[24] N. Al-Ajmi, M. Ahmadi, E. Ozkan, and H. Kazemi, "Numerical inversion of laplace transforms in the solution of transient flow problems with discontinuities," in Proceedings of the SPE Annual Technical Conference and Exhibition, Paper SPE 116255, pp. 2124, Denver, Colorado, 2008. 


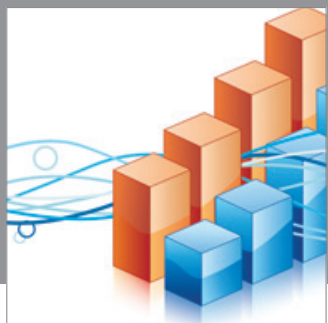

Advances in

Operations Research

mansans

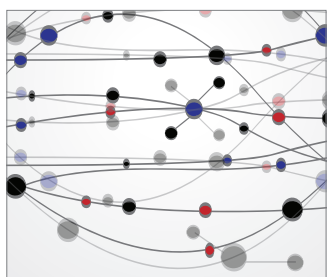

The Scientific World Journal
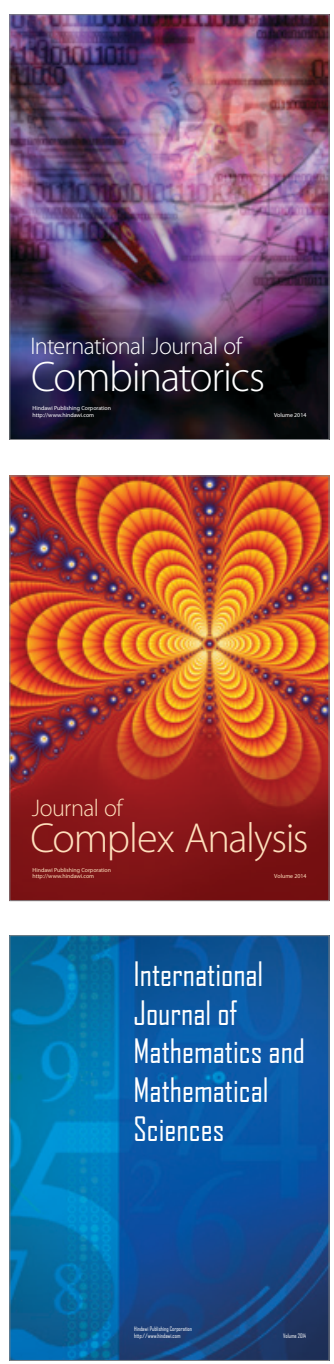
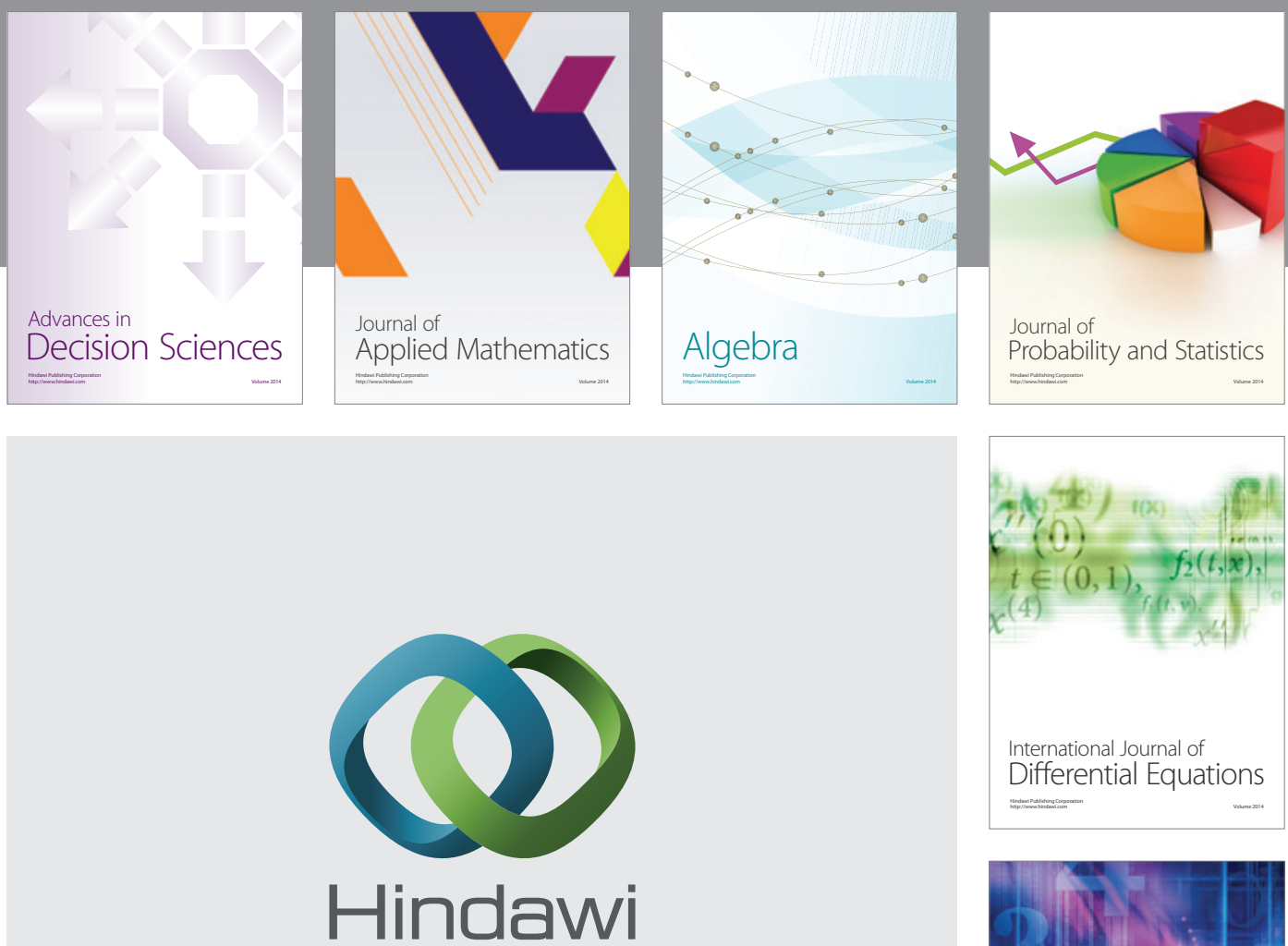

Submit your manuscripts at http://www.hindawi.com
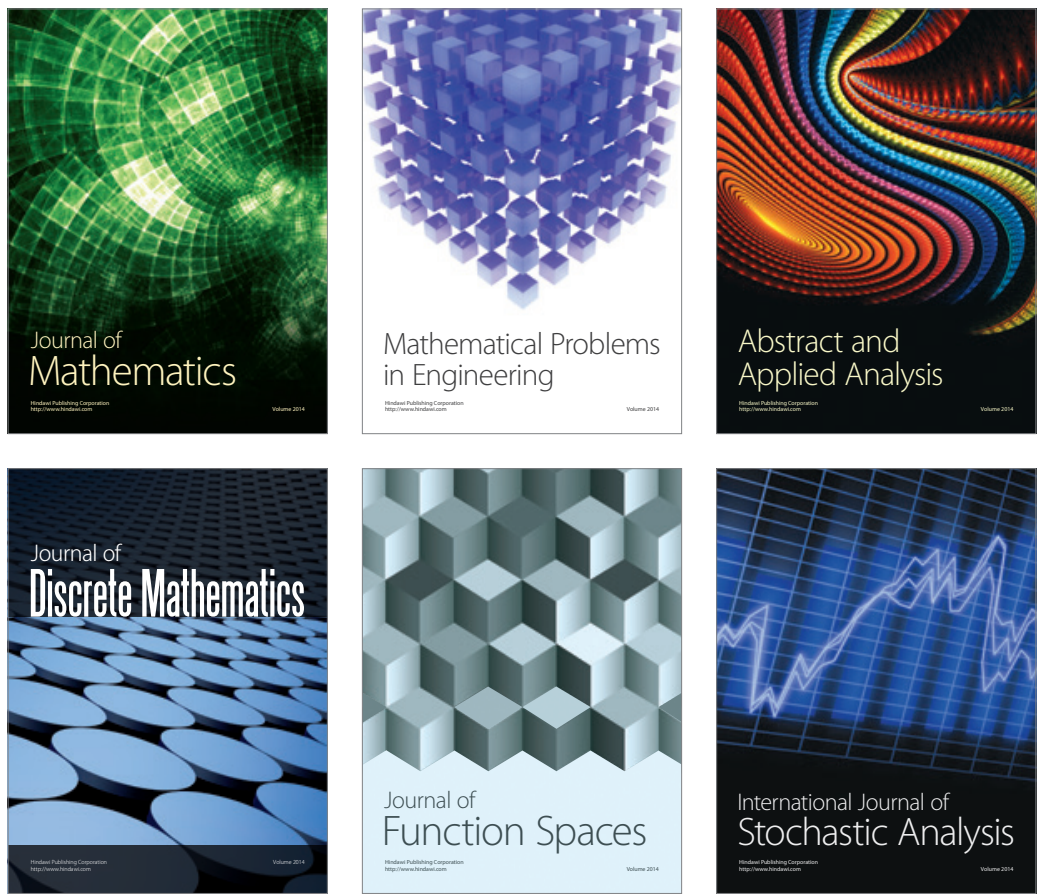

Journal of

Function Spaces

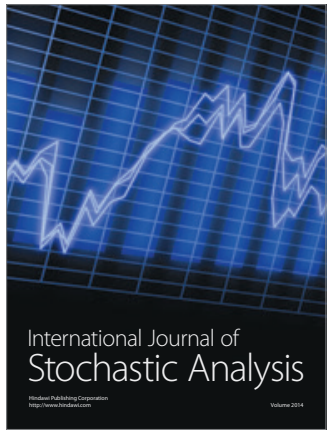

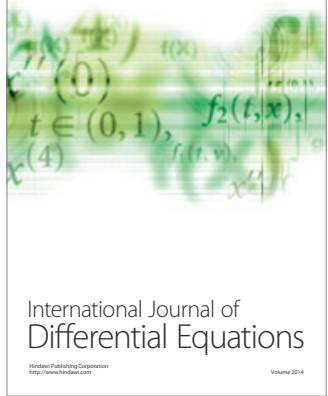
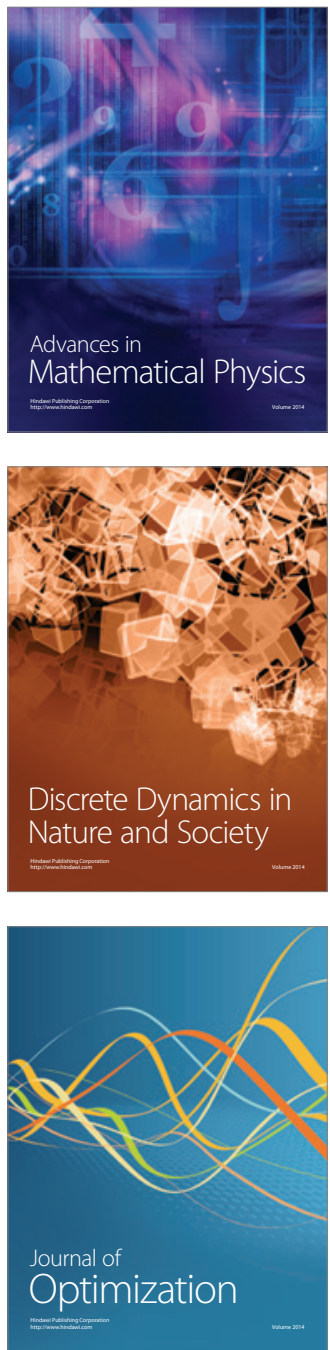